\title{
Structure-specific modules as indicators of promoter DNA in bacterial genomes
}

\author{
Kiselev S.S., Ozoline O.N." \\ Institute of Cell Biophysics, Russian Academy of Sciences, Pushchino, \\ Moscow region, 142290, Russia
}

\begin{abstract}
A unified version of promoter-search software, exploiting evolutionary conservation in the structural organization of bacterial transcription machinery is suggested (PlatPromU). In contrast with the initial algorithm PlatProm, optimized for recognition of $\sigma^{\mathrm{D}}$-dependent promoters in the genome of Escherichia coli (E.coli), modified version does not use weight matrices, reflecting the occurrence frequency of consensus base pairs within -10 and -35 elements. Its predicting potentiality was assessed by the ability to recognize the known promoters of Corynebacterium glutamicum (C.glutamicum) - evolutionarily distant from E.coli microorganism. «Sensitivity» of PlatPromU appeared to be comparable with that of specialized program (PlatPromC), adapted for recognition of C.glutamicum regulatory sites, and higher than predicting potentiality of initial algorithm PlatProm. Unified program, modeling only structural and conformational features of promoter DNA, may, therefore, be recommended as a tool for preliminary mapping of regulatory sites in genomes with unknown context of specific elements.
\end{abstract}

Key words: unified promoter search algorithm, the bacterial genome annotation.

\section{INTRODUCTION}

A computer-based search for promoters has now becoming an important instrument for genome annotation. With equal efficiency it can reveal transcription initiation sites for genes encoding proteins, rRNA and tRNA, as well as promoters, controlling synthesis of untranslated, antisense and alternative RNA-products [1, 2]. However, most promoter finders explore sequence motifs specifically recognized by $\sigma$-subunits of RNA polymerase as the main indicators of promoter DNA. In spite of apparent evolution stability of the transcription machinery, the context of these motifs varies noticeably both for promoters of different bacteria and for promoters recognized by different types of $\sigma$-factors within one and the same microorganism [3]. That means that algorithms searching promoters of a particular type should be specifically adapted for the context of their conservative elements. This necessity in a specific adaptation essentially restrains the usage of computational approaches as a valid annotation tool.

In this study we suggest the approach opening an opportunity to overcome this limitation using algorithm PlatProm, initially adapted for $\sigma^{\mathrm{D}}$-dependent promoters of E.coli. In addition to consensus hexanucleotides, forming specific contacts with $\sigma$-subunit of RNA polymerase, PlatProm takes into account conformational features of the promoter DNA. Due to evolution stability of RNA polymerases and universal structural organization of transcription machinery in different microorganisms, these features may be invariant or very similar in different

\footnotetext{
*ozoline@icb.psn.ru
} 
promoter types. The contribution of structure-specific elements in the PlatProm scores constitutes approximately 50\%. Full version of this software recognizes $85.5 \%$ of E.coli known promoters with $\mathrm{p}<0.0038$ reliability. If only structure-specific modules in the promoter DNA are taken into account, "sensitivity" of the program decreases, but still remains rather high $-62.4 \%$. Discriminative potentiality of structural modules provides thereby a chance to detect promoters without any contribution from the sequence-specific modules.

The genome of Corynebacterium glutamicum was used to test predictive potentiality of the unified program. In this genome 160 promoters of the main $\sigma$-factor - SigA (a counterpart of $\sigma^{\mathrm{D}}$ in E.coli) were mapped by experimental techniques. This is enough to develop new version PlatPromC, specifically adapted to corresponding promoters. The ability of unified version PlatPromU to find the regulatory sites of C.glutamicum was compared with that of specified version (PlatPromC), as well as with predictive potentiality of PlatProm algorithm. For this reason a new method of determining threshold levels, which ensure selection of transcriptional signals with equal statistical significance in the outputs of different search programs, was developed. The scores exceeding this level for 3, 4 and 5 standard deviations (StD) were considered as significant. Adapted program PlatPromC was most effective at the first level of reliability, but more stringent criteria made unified program more efficient, thus opening a way to suggest it for annotation procedures.

\section{METHODS}

\subsection{Genome of C.glutamicum and promoters}

The nucleotide sequence of the genomic DNA of C.glutamicum ATCC 13032 (NC_003450 in NCBI database [4]) was used for scanning and corresponding gene map for subsequent analysis. This genome is 3309401 base pairs (bp) long and contains $53 \%$ of G/C bp. Coordinates of the transcription start points for known promoters of C.glutamicum were taken from the original papers (table 1). Nucleotide sequences of promoters were obtained using auxiliary program DNA Tools (developed by A.A. Deev).

Table 1. Coordinates of the experimentally mapped transcription initiation points for sigAdependent promoters of Corynebacterium glutamicum

\begin{tabular}{|c|c|c|c|c|c|c|c|c|}
\hline Prom. & $\begin{array}{c}\text { Start point } \\
\text { and direction }\end{array}$ & $\mathrm{R}^{\mathrm{a}}$ & Prom. & $\begin{array}{l}\text { Start point } \\
\text { and direction }\end{array}$ & $\mathrm{R}^{\mathrm{a}}$ & Prom. & $\begin{array}{l}\text { Start point } \\
\text { and direction }\end{array}$ & $\mathrm{R}^{\mathrm{a}}$ \\
\hline $\operatorname{cg} 0042$ & $29965(-)$ & 5 & narK & $1253952(-)$ & 19 & $\mathrm{P}-45^{\mathrm{b}}$ & $2346400(-)$ & 7 \\
\hline$c g 0043$ & $29995(+)$ & 5 & atpl & $1271835(+)$ & 20 & $g \ln A$ & $2348721(+)$ & 7 \\
\hline citH & $70350 / 2 / 3^{c}(-)$ & 6 & atp2 & $1272131(+)$ & 10 & thrC & $2355050(-)$ & 7 \\
\hline $\mathrm{P}-45^{\mathrm{b}}$ & $194354(+)$ & 7 & ssuDl & $1283324(+)$ & 18 & aceE & $2379862(+)$ & 34 \\
\hline gltB & $195199(+)$ & 7 & $p f k A$ & $1315055(+)$ & 16 & $a e c D$ & $2444605(+)$ & 14 \\
\hline$d c c T$ & $239837(+)$ & 8 & $r b s R$ & $1316264(+)$ & 19 & $r b s K 2$ & $2463200(+)$ & 25 \\
\hline leuA & $268136(-)$ & 7 & lysE & $1328945(-)$ & 7 & aceB-P3 & $2470325(-)$ & 11 \\
\hline orfMP & $269124(-)$ & 7 & lys $G$ & $1329000(+)$ & 7 & $a c e B-P 2$ & $\begin{array}{c}2470608 / 10 \\
(11)(-)\end{array}$ & $\begin{array}{l}11 \\
(7)\end{array}$ \\
\hline askPl & $269333(-)$ & 7 & $i l v B$ & $1337840(+)$ & 7 & aceA & $2470630(+)$ & 7 \\
\hline askP2 & $270071(+)$ & 7 & $i l v C$ & $1340628(+)$ & 7 & $m d h$ & $2523282(-)$ & 35 \\
\hline $\operatorname{lrp}$ & $276754(-)$ & 7 & leuB & $1353454(+)$ & 7 & pcaHG & $2541084(-)$ & 36 \\
\hline brnF & $276829(+)$ & 7 & $l t b R$ & $1380259(-)$ & 20 & $\operatorname{clpPl}$ & $2556624(-)$ & 32 \\
\hline brnE & $277614(+)$ & 7 & leuC & $1380380(+)$ & 20 & metB & $2591526(-)$ & 14 \\
\hline$g l x R$ & $307582(-)$ & 9 & $p t s G$ & $\begin{array}{c}1422959 \\
(61,62)(+)\end{array}$ & $\begin{array}{l}23, \\
24, \\
16\end{array}$ & malE1 & $2608051(-)$ & 37 \\
\hline$u \operatorname{sh} A$ & $343576(+)$ & 10 & uriR & $1432678(-)$ & 25 & gntK-P2 & $2630572(+)$ & 38 \\
\hline$l p d A$ & $387692(+)$ & 7 & ugpA & $1450890(+)$ & 10 & gntK-Pl & $2630620(+)$ & 39 \\
\hline
\end{tabular}


STRUCTURE-SPECIFIC MODULES AS INDICATORS OF PROMOTER DNA IN BACTERIAL GENOMES

\begin{tabular}{|c|c|c|c|c|c|c|c|c|}
\hline $\operatorname{ramB}$ & $392208(-)$ & 9 & metH & $1591237(-)$ & 14 & cg2782 & $2674805(+)$ & 12 \\
\hline$s d h C$ & $392690(+)$ & 11 & $a c n$ & $1626169 / 72(+)$ & 26 & gpm & $2690077(-)$ & 16 \\
\hline cg0527 & $471013(-)$ & 12 & acnR & $1629247(+)$ & 11 & cg2810 & $2699615(-)$ & 40 \\
\hline $\sec E$ & $496793(+)$ & 7 & sufR 1 & $1653617(-)$ & 27 & $\operatorname{ram} A$ & $2721299(-)$ & 41 \\
\hline $\mathrm{P}-13$ & $597651(+)$ & 7 & $a m t$ & $1676679(-)$ & 7 & sucC & $2726673(-)$ & 11 \\
\hline groESL & $610252(+)$ & 13 & $p g k-P 1$ & $1682462(-)$ & 7 & pstS & $2737620(-)$ & 10 \\
\hline $\mathrm{P}-2$ & $632028(-)$ & 7 & $p g k-P 2$ & $1682499(-)$ & 16 & писH & $2753958(+)$ & 10 \\
\hline metX & $666353(-)$ & 14 & gapA & $1683809(-)$ & 7 & $d c t A$ & $2759320(-)$ & 42 \\
\hline met $Y$ & $667809(-)$ & 14 & metK & $1700445(-)$ & 14 & phoR & $2774859(-)$ & 10 \\
\hline metY2 & $667832(-)$ & 14 & cg1935 & $1813663(+)$ & 28 & $p q o$ & $2778550(-)$ & 43 \\
\hline$m d h B$ & $676145(-)$ & 11 & $\mathrm{P}-10$ & $1868922(-)$ & 7 & cgl2611 & $2778968(+)$ & 44 \\
\hline$i c d$ & $680075(-)$ & 11 & $\operatorname{sig} A$ & $2011495(+)$ & 7 & thrE & $2790923(+)$ & 7 \\
\hline cg0771 & $684976(-)$ & 12 & $\operatorname{div} S-P 1$ & $2036434(-)$ & 29 & cg2911 & $2796866(+)$ & 5 \\
\hline pyc & $705155(+)$ & 7 & $\operatorname{div} S-P 2$ & $2036503(-)$ & 29 & $p t s S$ & $2811869(-)$ & 24 \\
\hline cg0794 & $711644(-)$ & 5 & $\operatorname{lex} A$ & $2036607(+)$ & 29 & $\operatorname{clp} C$ & $2846977(-)$ & 32 \\
\hline cg0795 & $711669(+)$ & 5 & sugR & $2037767(+)$ & 30 & porH & $2888411(-)$ & 45 \\
\hline cg0922 & $850279(-)$ & 12 & ptsI-P2 & $2041349(-)$ & 24 & groEL2 & $2890687(-)$ & 13 \\
\hline gltA-P2 & $877479(+)$ & 15 & ptsI-PI & $2041415 / 7(-)$ & 24 & pta2 & $2938094(-)$ & 46 \\
\hline gltA-P1 & $877715(7)^{\mathrm{d}}(+)$ & $\begin{array}{l}15 \\
7\end{array}$ & fruR-Pl & $\begin{array}{c}2041435 / 6 \\
(8)(+)\end{array}$ & $\begin{array}{l}24, \\
30\end{array}$ & ptal & $2937982(-)$ & 46 \\
\hline $\mathrm{P}-1 \mathrm{~A}$ & $939686(+)$ & 7 & fruR-P2 & $2041602 / 5(+)$ & 24 & $\mathrm{P}-22 \mathrm{~A}$ & $2944795(-)$ & 7 \\
\hline$r p f 2$ & $963782(+)$ & 7 & cgl1934 & $2041640(+)$ & 31 & $f d a$ & $2955421(-)$ & 7 \\
\hline $\operatorname{gapB}$ & $993092(+)$ & 16 & $p t s H$ & $2045635(+)$ & 30 & ald & $2981791(-)$ & 47 \\
\hline P-34 & $1034563(+)$ & 7 & ptsH-Pl & $2045660(+)$ & 24 & dnaK & $2986507(-)$ & 13 \\
\hline eno & $1034879(+)$ & 16 & ptsH-P2 & $2045680(+)$ & 24 & adhA & $2996912(-)$ & 48 \\
\hline P-64 & $1045560(+)$ & 7 & $\operatorname{clg} R$ & $2069968(-)$ & 32 & cysI & $3005214(-)$ & 49 \\
\hline glyA & $1050560(+)$ & 17 & dapA & $2080183(-)$ & 7 & fpr2 & $3005440(+)$ & 49 \\
\hline fum & $1063654(-)$ & 11 & dapB2 & $2081925(-)$ & 7 & $t c t C$ & $3012908(-)$ & 6 \\
\hline ssuI & $1063936(+)$ & 18 & dapB1 & $2081974(-)$ & 7 & $\mathrm{P}-45^{\mathrm{b}}$ & $3033754(+)$ & 7 \\
\hline $\operatorname{seu} A$ & $1066071(+)$ & 18 & $m q o$ & $2115532(-)$ & 11 & $p c k A$ & $3053929(-)$ & 16 \\
\hline ssuD2 & $1069959(+)$ & 18 & $g d h$ & $2196368(-)$ & 7 & gntP & $3108088(+)$ & 39 \\
\hline $\mathrm{P}-75$ & $1102054(+)$ & 7 & $i l v A$ & $2246172(-)$ & 7 & $\operatorname{ldh} A$ & $\begin{array}{c}3113479 \\
(83)(-)\end{array}$ & $\begin{array}{l}30, \\
35\end{array}$ \\
\hline pgm & $1107515(+)$ & 16 & ftsZ1 & $2280258(-)$ & 33 & cgl2816 & $3118211(+)$ & 50 \\
\hline $\begin{array}{l}\text { orf3- } \\
\text { aroP }\end{array}$ & $1155750(-)$ & 7 & ftsZ2 & $2280457(-)$ & 33 & cg3327 & $3201755(-)$ & 12 \\
\hline odhA & $1176370(-)$ & 11 & ftsZ3 & $2280503(-)$ & 33 & malE & $3208210(+)$ & 16 \\
\hline metE & $1190662(-)$ & 14 & ftsZ4 & $2280648(-)$ & 33 & trp & $3233129(+)$ & 7 \\
\hline $\arg S$ & $1238270(+)$ & 7 & ftsZ5 & $2280729(-)$ & 33 & cg3372 & $3248349(+)$ & 40 \\
\hline hom & $1242420(+)$ & 7 & metF & $2299526(-)$ & 14 & & & \\
\hline thrB & $1243843(+)$ & 7 & $s u c B$ & $2339224(+)$ & 11 & & & \\
\hline
\end{tabular}

«a $\rangle-$ reference to literary source, $\langle\mathrm{b} »-$ promoter P-45 present in a three copies, «c» - multiple start points, «d»-start points given in different sources.

\subsection{Design of PlatProm weight matrices}

Correspondence of genomic sequences to conservative hexanucleotides -35 and -10 , forming the specific contacts with the $\sigma$-subunit of RNA polymerase, was estimated using position weight matrices (PWM). Their occurrence frequencies (weights) were calculated the same way as proposed by Hertz and Stormo [51]. Each of these matrices possesses 24 parameters $k_{i j}$, determined as:

$$
k_{i j}=\ln \left(f_{i j} / n_{j}\right),
$$


where $i$ - nucleotide position in the element, $j$ - particular nucleotide (A, C, G или T), $f_{i j}-$ occurrence frequency of nucleotide $j$ in position $i, n_{j}$ - normalization coefficient, reflecting the occurrence frequency of $j$ in analyzed genome.

The correspondence of analyzing nucleotide sequences to the consensus elements is estimated as a sum of contributions given by all pairs located in regions of expected disposition of conserved modules:

$$
K_{c}=\sum_{i}^{12} \sum_{j}^{4} k_{i j}
$$

where $k_{i j}$ - weight of the nucleotide, located in the analyzed position and calculated by the formula (1), or 0 (the possibility of summation is provided for degenerative alphabets).

The variations in spacer (S) length between -35 and -10 elements (allowed range $14 \leq \mathrm{S} \leq 21$ ) and distance (D) between -10 element and the transcription start point (allowed range $2 \leq \mathrm{D} \leq 9$ ) were taken into account using weight matrices, reflecting occurrence frequencies of different distances in the training set of promoters:

$$
K_{S(D)}=\ln \left(N_{S(D)} / N_{17(6)}\right),
$$

where $N_{S(D)}$ - the number of promoters with corresponding $\mathrm{S}$ and $\mathrm{D}, N_{17(6)}$ - the number of promoters with optimal $\mathrm{S}(17 \mathrm{bp})$ and $\mathrm{D}(6 \mathrm{bp})$.

Any deviation from the optimal values of S or D decreased the total score on the value of $K_{S(D)}$. Since the number of promoters with very long or very short positional distances is rather small, their real $K_{S(D)}$ gave very high negative contributions, which impaired alignment in respect to conservative hexanucleotides. That is why, the value of $K_{S}$ for all promoters with spacer length $>18 \mathrm{bp}$ was set equal to $K_{S}$, calculated for promoters with $\mathrm{S}=18 \mathrm{bp}$, while for promoters with $\mathrm{S}<16$ bp $K_{S}$ was equated to promoters with $\mathrm{S}=16$. Dependence on $\mathrm{D}$ was reduced by the same manner. For promoters with $\mathrm{D}=4,5,7$ or 8 , values of $K_{D}$ were calculated according to occurrence frequency of corresponding promoters in the compilation. $K_{D}$ for promoters with $\mathrm{D} \leq 3$ was set equal to $K_{D}$ of promoters with $\mathrm{D}=4$, while $K_{D}$ of promoters with $\mathrm{c} \mathrm{D}=9$ was equated to promoters with $\mathrm{D}=8$.

The computation of the optimal PWM was performed by the method of successive iterations. PWMs of the first step were calculated manually on the basis of 30 promoters, which conservative hexanucleotides were found experimentally by genetic techniques. Modules identified by PlatProm as a consensus hexanucleotides in the promoters of learning compilation (308 non-homologous and non-overlapping sequences), were used by the program to generate refined PWMs (first iteration). These PWMs were used in the next step and so on up to the full stabilization of occurrence frequencies in subsequent steps.

Peculiarities in the nucleotide sequence nearby transcription start points were accounted by one-dimensional weight matrix, which parameters $\left(k_{d i}\right)$ reflect the occurrence frequency of 16 dinucleotides in the position -1 :

$$
k_{d i}=\ln \left(f_{d i} / n_{d i}\right),
$$

Where $d i$ - particular dinucleotide, $f_{d i}$ - occurrence frequency of $d i$ in position -1 in the promoter compilation, $n_{d i}$ - occurrence frequency of $d i$ in genome.

The presence of functionally important dinucleotide TG in the 5'-flanking region of -10 element $\left(k_{\mathrm{TG}}\right)$ was accounted by the same way.

Along with elements listed above, PlatProm takes into account specific conformational features of promoter DNA, as well as the modules, favoring transcription complex formation and its transition to the productive initiation [1-3, 52-56]. These elements include:

- regular distribution of polyA(T)-tracts, which interact with RNA polymerase $\alpha$-subunits or stabilize the transcription complex by a properly induced bend; 
- flexible YR-dinucleotides ( $\mathrm{Y}=\mathrm{C}=\mathrm{T}, \mathrm{R}=\mathrm{A}=\mathrm{G}$ ), which support adaptive isomerization of the DNA helix upon interaction with RNA polymerase or regulatory proteins;

- periodic distribution of mixed A/T-tracts, hypothetically participating in RNA polymerase sliding along the DNA;

- direct and inverted repeats as a putative targets for interaction with transcription factors;

- other dominant motives previously revealed for E.coli promoters by cluster analysis [56].

Table 2. Cascade weight matrix, reflecting the heightened occurrence frequency in the presence of flexible steps within -55/-52 promoter region

\begin{tabular}{|c|c|c|}
\hline Position & $\begin{array}{c}\text { Sequence } \\
\text { module }\end{array}$ & $\begin{array}{c}\text { Normalized logarithm of the occurrence } \\
\text { frequency in promoters }\end{array}$ \\
\hline-53 & ACAT & 1,56 \\
\hline-56 & CACA & 0,90 \\
\hline-52 & CAT & 0,89 \\
\hline-56 & TCAT & 0,70 \\
\hline-55 & CAT & 0,61 \\
\hline-57 & ACAC & 0,44 \\
\hline-57 & ACA & 0,18 \\
\hline All elements absent & $-0,036$ \\
\hline
\end{tabular}

Sequence elements were considered as a promoter-specific, if their occurrence frequency in the particular position of the promoter DNA (the range of analyzed area: $-250 /+150$ according to the start point of transcription) was at least 5 standard deviations (StD) higher than background level. All of them are taken into account by 60 cascade matrices (exemplified in table 2), which differ from usual PWMs by containing frequency weights for only dominating motifs (calculated as normalized natural logarithm of occurrence frequency for a particular sequence element in the fixed promoter position). If scrutinized sequence possesses several overlapping motifs (for instance, ACAT-53 and $\mathrm{CAT}_{-52}$, table 2), the contribution to the total score gives only that one, which weight in the promoter compilation is higher (ACAT). An absence of all promoter-specific motifs in a particular sequence is penalized by the negative contribution quantified as a logarithm of the portion of such promoters in the training set.

The total score was calculated as a sum of contributions given by all weight matrices, balanced by such a way, so as an overall contribution of the cascade matrices appeared to be $\sim 50 \%$. For this reason, the contribution of the every cascade matrix was normalized per the relative information content of corresponding promoter region and that of the last base pair in the -35 element (the least conservative base pair). Information content was calculated by the algorithm, suggested in [57].

\subsection{Estimation of the statistically significant threshold level}

Two sets of sequences were previously used to estimate the background level and StD, typical for non-promoter DNAs [1]. The first of them (CS1) was composed of 273 fragments of coding sequences taken from convergent E.coli genes longer than $700 \mathrm{bp}$, which are separated by at least $50 \mathrm{bp}$ intergenic space. The probability of coming across a functional promoters within such genes is minimal. The second set contained 400 random sequences with the same AT/GC-content as in the studied genome. Each of these two sets has certain advantages and limitations. An advantage of the first compilation is its biological authenticity but already annotated genome is required to collect natural sequences and available number may be less than required for statistical analysis. Any size set of random sequences can be 
easily obtained computationally but generated fragments with certain probability will contain promoter-like sequences, which non-random distribution in genomes is controlled by evolution. In this work we suggest the novel method of threshold levels determination. Its essence is to select natural sequences, which have minimal probability to function as promoter DNA. For this purpose the mean value of score $(F)$ and StD was estimated for $1000 \mathrm{bp}$ long fragments (average length of a gene) using the sliding window mode of calculations. Then the genome was partitioned per the segments of equal length, and position with minimal $F\left(F_{\min }\right)$ was found within each of them (exemplified in fig. 1). The mean value of $F_{\min }$ across the whole genome $(\bar{F})$ was considered the background level, while the mean value of corresponding StDs characterized variability of the PlatProm scores in non-promoter regions.

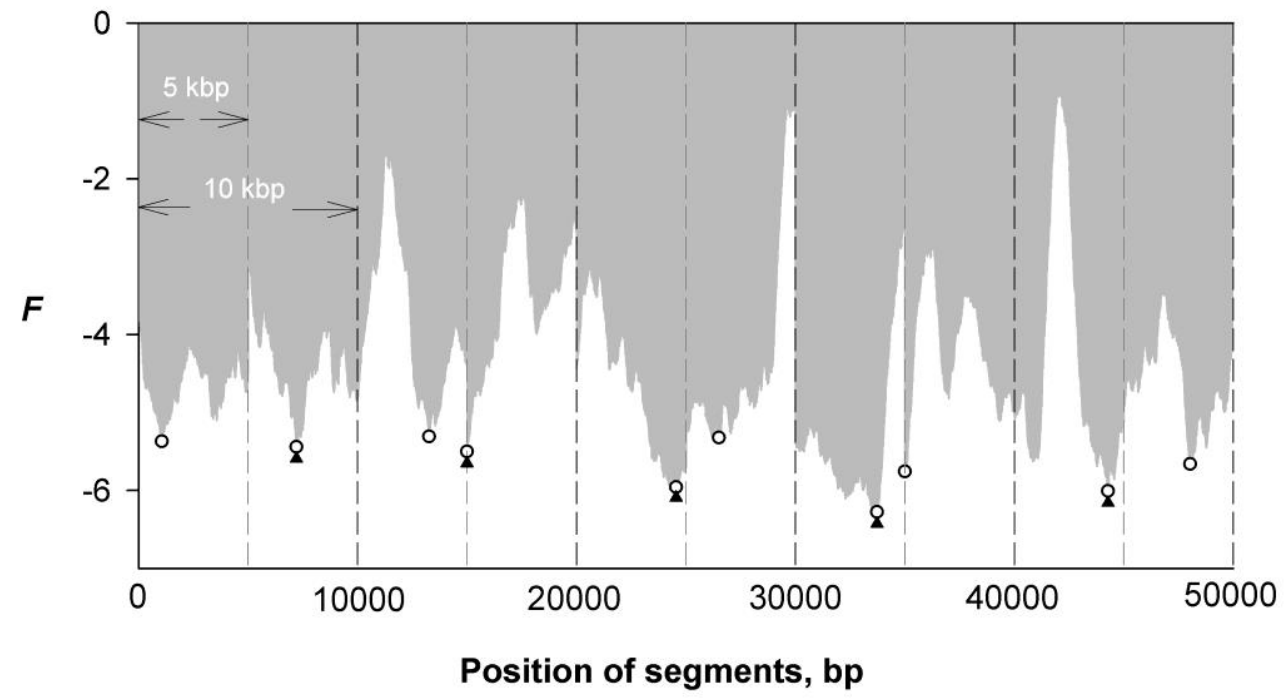

Figure 1. Searching for non-promoter regions in the first $50000 \mathrm{bp}$ of the E.coli MG1655 genome (NC_000913 in [4]). Grey bars represent an average score within 1000 bp fragments. Local minima $\left(F_{\min }\right)$, revealed within 5000 and 10000 bp segments are marked by circles and triangles, respectively.

The values of StD did not show essential dependence on the partitioning density, while the value of $F_{\min }$ tend to decrease with increased length of the segments (fig. 1, table 3). To select an optimal density, the values of $\bar{F}$ given by different segmentations were compared with the background level quantified on the basis of CS1. The closest values were found in the case, when genome of E.coli was partitioned by 5000 bp segments, so such values of $\bar{F}$ were used to calculate the three thresholds $(L)$ after scanning of the C.glutamicum genome by different PlatProm versions:

$$
L_{n}=\bar{F}+n \mathrm{StD}, n=3,4 \text { and } 5 \text {. }
$$

Table 3. Dependence of $\bar{F}$ and StD on the segmentation density

\begin{tabular}{|c|c|c|c|}
\hline Segment length (bp) & $\bar{F}$ & StD & $\begin{array}{c}\text { Second threshold level } \\
\left(L_{2}\right)\end{array}$ \\
\hline \multicolumn{4}{|c|}{ Escherichia coli $\mathrm{K} 12$ MG1655 (PlatProm) } \\
\hline 5000 & $-5,41$ & 3,27 & 7,67 \\
\hline 10000 & $-5,76$ & 3,24 & 6,2 \\
\hline 20000 & $-6,04$ & 3,21 & 6,45 \\
\hline 50000 & $-6,35$ & 3,20 & 6,37 \\
\hline \multicolumn{5}{|c|}{ Corynebacterium glutamicum ATCC 13032 (PlatPromC) } \\
\hline 5000 & $-4,14$ & 2,63 & 6,04 \\
\hline 10000 & $-4,40$ & 2,61 & 5,78 \\
\hline 20000 & $-4,62$ & 2,60 & 5,44 \\
\hline 50000 & $-4,91$ & 2,59 & \\
\hline
\end{tabular}




\subsection{Adaptation of the PlatProm PWMs to the context of C.glutamicum -35 and -10 modules}

Assuming invariant structural organization in the bacterial transcription machinery, only PWMs of the PlatProm were adapted to the context of C.glutamicum promoters. Initially these matrices were designed using training set composed of 308 known E.coli promoters (see above), while "sensitivity" of the program was estimated using test compilation, composed of 290 non-overlapping and non-homologous E.coli promoters, absent in the training set $[1,2,52]$. But restricted amount of experimentally mapped promoters in C.glutamicum genome (a total of 160 sequences of which 3 identical) not allowed to compose two independent compilations. Thus the strategy of alternate targets was used to test the quality of specialized program. In this case each known promoter in turn was considered as a testing sample, while remaining 157 sequences were used to quantify PWMs. But through-genome scan with a purpose to determine the background level was made by a specialized version of the program (PlatPromC), which was designed based on all 158 promoters.

\subsection{Unification of PlatProm}

The design of the unified algorithm is a complex multistep program, which implementation may require accounting of additional factors or, perhaps, further simplification of the PlatProm scoring system. As a first step in this study we validated predictive capacity of the program PlatPromU using only cascade matrices of PlatProm.

\subsection{Criteria used to estimate predictive capacity of computer algorithms}

"Sensitivity" of the programs used was estimated as a percentage of promoters identified at different levels of reliability. Scores, exceeding the background level by 3, 4 or 5 StDs ( $\mathrm{p}<0.0014, \mathrm{p}<0.00004$ and 0.000001 , respectively) were considered as significant. Promoters was considered as recognized, if predicted point of the transcription initiation laid in the range \pm 5 bp nearby the experimentally mapped start. Since experimental identification of the RNAs 5'-ends is associated with some inaccuracy, the promoter was considered as accurately recognized by computer program, if the position of predicted start coincided or was located within 2 bp region nearby experimental point.

\section{RESULTS}

Fig. 2 exemplifies the distribution of significant scores in front of C.glutamicum gene phoR, encoding phosphate regulon sensor kinase-phosphotransferase. The transcription start point of this gene is located 44 bp upstream of the initiating codon ATG [10].

All three algorithms (PlatPromC, PlatProm and PlatPromU) revealed promoter-like site alongside of phoR. But E.coli-specific algorithm (PlatProm) overlooking the real transcription initiation point (position -44 ) offers the position -75 as the most probable start (middle plot in fig. 2). Specialized program PlatPromC accurately identifies the real start (red bar in the top plot of fig. 2), while also predicts transcription initiation at position -74 . The score in this position exceeds the background level by $4.99 \mathrm{StD}$, which corresponds to $\mathrm{p}<0.000001$. That means that only 7 promoter-like signals with the same amplitude may be found in the genome of C.glutamicum by chance. The probability for this signal to be a false positive is, therefore, very low, especially as unified program (bottom plot in fig. 2) predicted this additional start (and the real point of transcription initiation) with very high reliability. Most probably that means that phoR expression may be controlled by two tandem promoters. 

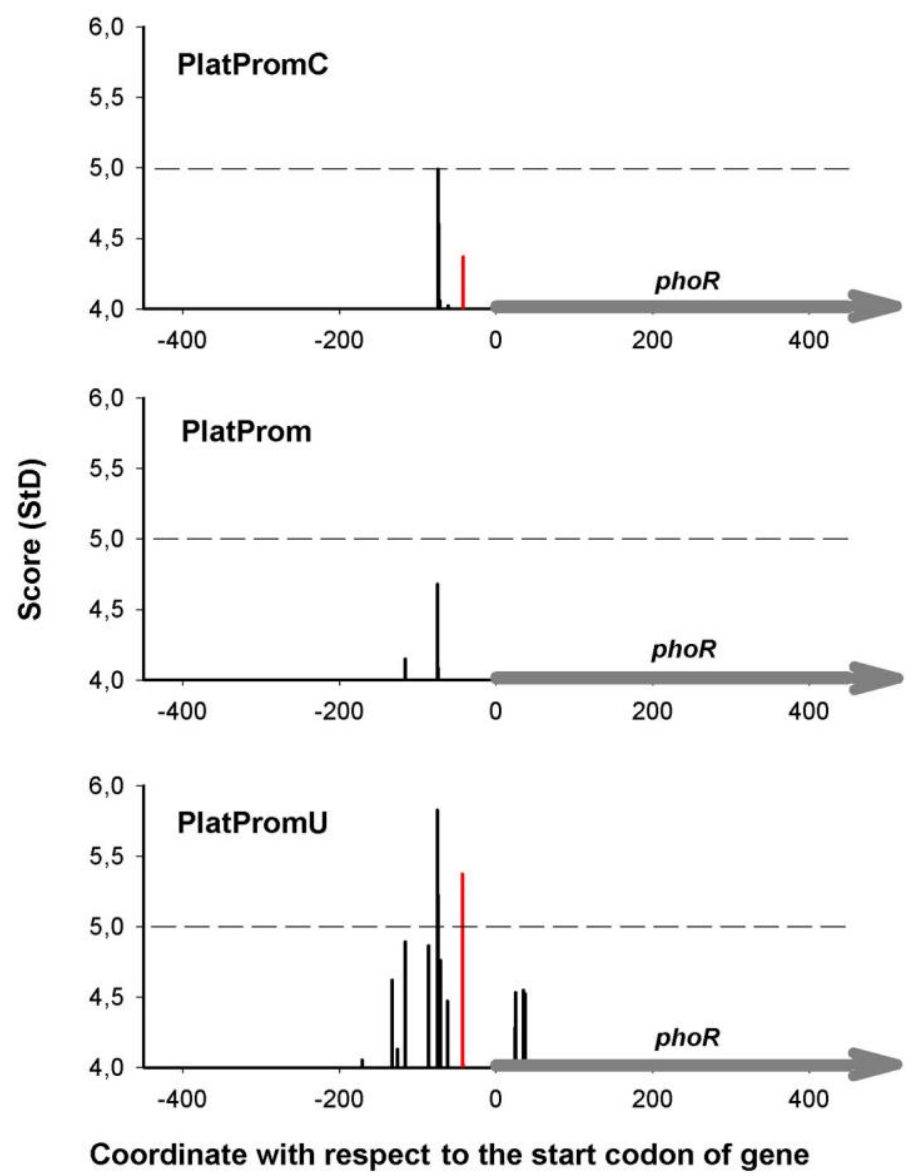

Figure 2. Transcription start points predicted by three algorithms for the C.glutamicum gene phoR (gray arrow). Red colour marks the real transcription start point. The X-axis corresponds to the second level of reliability $(\bar{F}+4 \mathrm{StD})$, dashed line delineates the third level $(\bar{F}+5 \mathrm{StD})$.

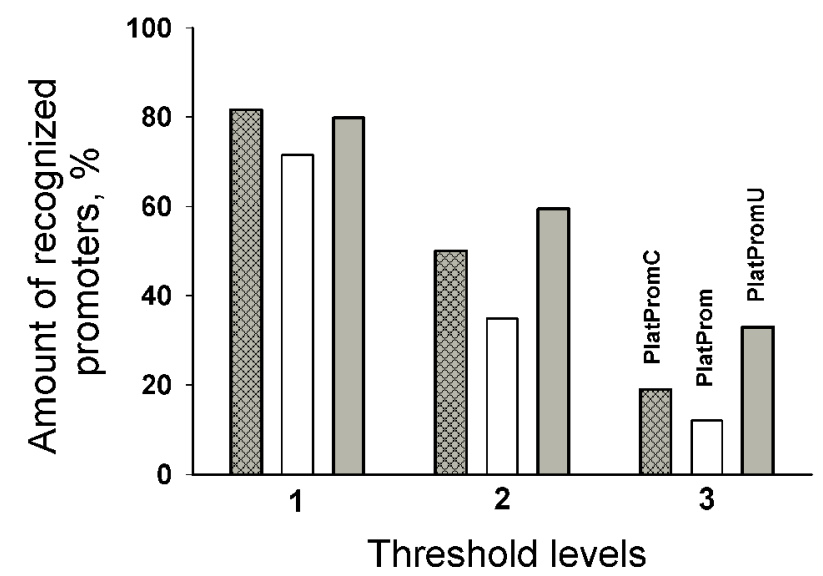

Figure 3. An ability of PlatPromC, PlatProm and PlatPromU (indicated on the plot) to recognize C.glutamicum promoters at different levels of reliability. Signals, exceeding the background level $(\bar{F})$ by 3, 4 and 5 StDs were considered significant at threshold levels 1, 2 and 3, respectively.

Fig. 3 demonstrates the summary of comparative analysis. At the first level $(\mathrm{p}<0.0014)$ adapted program PlatPromC (hatched bars) was most effective. It identifies $81.6 \%$ promoters, i.e. as much as PlatProm at the same cut off level ( $81 \%$, data not shown) recognizes in the test compilation, composed of E.coli promoters. That means that cascade matrices of PlatPromC, which remain «tuned» to the conformational features of E.coli promoters, are equally discriminative for promoters of C.glutamicum. Their use in combination with E.coli-specific PWMs significantly decreased predictive capacity of the program (white bars). This is 
consistent with the generally accepted view, which assumes relevance of the specific adaptation for the promoter search algorithms. «Sensitivity» of the unified program, operating with only cascade matrices (grey bars), at the first cut off level was almost the same as «sensitivity» of adapted algorithm (79.7\%), while at higher levels even exceeded it. That means that the structure-specific modules in the promoter DNA, scored by the cascade matrices, indeed, may be used as efficient indicators.

\section{DISCUSSION}

The study presents the first version of the unified software with ability to point out transcription initiation sites within the genomes with poorly characterized or completely unknown regulatory elements. For this purpose a simplified version of the PlatProm was used. PWMs, estimating a correspondence of nucleotide sequences to the consensus -10 and -35 elements of E.coli $\sigma^{\mathrm{D}}$-dependent promoters, in the simplified version were switched off. Performance of the program was tested using promoters of C.glutamicum. This Gram-pozitive microorganism belongs to the phylum Actinobacteria, while Gram-negative E.coli is a Gammaproteobacteria. A predictive capacity of unified version was, therefore, evaluated in the strict conditions of heterologous genetic system. The data obtained, with no doubt, indicate that the structural features of promoter DNA may be used to point out transcription initiation sites. However, a majority of currently used structure-specific modules are enriched by A/T-pairs. Thus, it is not yet clear, how efficiently the unified program will be able to find promoters in the genomes with heightened and, conversely, lowered GC-content.

The analysis of the data obtained revealed higher tendency of transcription signals, found by the unified program, to form extensive clusters, than that of specialized algorithms (fig. 2). The presence of clustered transcription signals nearby the real promoters has long been known and discussed $[1,58,59]$. It has been speculated that overlapping promoter-like sites are used by cell transcription machinery to increase local concentration of RNA polymerase hereabout transcribed genomic regions [58, 59]. Along with this phenomenon, in the genome of E.coli genome we discovered abnormally long ( $\geq 300 \mathrm{bp})$ «promoter islands» [1]. Efficiently interacting with RNA polymerase they exhibited paradoxically low transcription activity [1]. It is not excluded that these novel structural elements perform some kind of specific biological role not necessarily associated with RNA synthesis. Comprehensive comparative screening of the «promoter islands» by unified and specific algorithms in different genomes may be useful in order to accept or reject an assumption on the involvement of these new genomic elements in the structural remodeling of chromosomal DNA.

The work was supported by Russian Foundation for Basic Research (grant 10-04-01218).

\section{REFERENCES}

1. Shavkunov K.S., Masulis I.S., Tutukina M.N., Deev A.A., Ozoline O.N. Gains and unexpected lessons in genome-scale promoter mapping. Nucleic Acids Res. 2009. V. 37. P. 4419-4431.

2. Ozoline O.N., Deev A.A. Predicting antisense RNAs in the genomes of Escherichia coli and Salmonella typhimurium using promoter-search algorithm PlatProm. J. Bioinf. Comput. Biol. 2006. V. 4. P. 443-454.

3. Ozoline O.N., Purtov Yu.A., Brok-Volchanski A.S., Deev A.A., Lukyanov V.I. Specifity of DNA-protein interactions within transcription complexes of Escherichia coli. Molecular biology. 2004. V. 38. P. 663-673.

4. URL: ftp://ftp.ncbi.nih.gov/genomes/Bacteria/.

5. Schroder J., Jochmann N., Rodionov D.A., Tauch A. The Zur regulon of Corynebacterium glutamicum ATCC 13032. BMC Genomics. 2010. V. 11. Article No. 12. 
6. Brocker M., Schaffer S., Mack C., Bott M. Citrate utilization by Corynebacterium glutamicum is controlled by the CitAB two-component system through positive regulation of the citrate transport genes citH and tctCBA. J. Bacteriol. 2009. V. 191. P. 3869-3880.

7. Patek M., Nesvera J., Guyonvarch A., Reyes O., Leblon G. Promoters of Corynebacterium glutamicum. J. Biotechnol. 2003. V. 104. P. 311-323.

8. Youn J.-W., Jolkver E., Kramer R., Marin K., Wendisch V.F. Identification and characterization of the dicarboxylate uptake system DccT in Corynebacterium glutamicum. J. Bacteriol. 2008. V. 190. P. 6458-6466.

9. Jungwirth B., Emer D., Brune I., Hansmeier N., Puhler A., Eikmanns B.J., Tauch A. Triple transcriptional control of the resuscitation promoting factor 2 ( $r p f 2$ ) gene of Corynebacterium glutamicum by the regulators of acetate metabolism RamA and RamB and the cAMP-dependent regulator GlxR. FEMS Microbiol. Lett. 2008. V. 281. P. 190197.

10. Kocan M., Schaffer S., Ishige T., Sorger-Herrmann U., Wendisch V.F., Bott M. Twocomponent systems of Corynebacterium glutamicum: deletion analysis and involvement of the PhoS-PhoR system in the phosphate starvation response. J. Bacteriol. 2006. V. 188. P. 724-732.

11. Han S.O., Inui M., Yukawa H. Transcription of Corynebacterium glutamicum genes involved in tricarboxylic acid cycle and glyoxylate cycle. J. Mol. Microbiol. Biotechnol. 2008. V. 15. P. 264-276.

12. Brune I., Werner H., Huser A.T., Kalinowski J., Puhler A., Tauch A. The DtxR protein acting as dual transcriptional regulator directs a global regulatory network involved in iron metabolism of Corynebacterium glutamicum. BMC Genomics. 2006. V. 7. Article No. 21.

13. Barreiro C., Gonzalez-Lavado E., Patek M., Martin J.-F. Transcriptional analysis of the groES-groEL1, groEL2, and dnaK genes in Corynebacterium glutamicum: characterization of heat shock-induced promoters. J. Bacteriol. 2004. V. 186. P. 413417.

14. Suda M., Teramoto H., Imamiya T., Inui M., Yukawa H. Transcriptional regulation of Corynebacterium glutamicum methionine biosynthesis genes in response to methionine supplementation under oxygen deprivation. Appl. Microbiol. Biotechnol. 2008. V. 81. P. 505-513.

15. Van Ooyen J., Emer D., Bussmann M., Botta M., Eikmanns B.J., Eggeling L. Citrate synthase in Corynebacterium glutamicum is encoded by two gltA transcripts which are controlled by RamA, RamB, and GlxR. J. Biotechnol. 2011. (in press).

16. Han S.O., Inui M., Yukawa H. Expression of Corynebacterium glutamicum glycolytic genes varies with carbon source and growth phase. Microbiology. 2007. V. 153. P. 2190-2202.

17. Schweitzer J.-E., Stolz M., Diesveld R., Etterich H., Eggeling L. The serine hydroxymethyltransferase gene glyA in Corynebacterium glutamicum is controlled by GlyR. J. Biotechnol. 2009. V. 139. P. 214-221.

18. Koch D.J., Ruckert C., Albersmeier A., Huser A.T., Tauch A., Puhler A., Kalinowski J. The transcriptional regulator SsuR activates expression of the Corynebacterium glutamicum sulphonate utilization genes in the absence of sulphate. Mol. Microbiol. 2005. V. 58. P. 480-494.

19. Nishimura T., Vertes A.A., Shinoda Y., Inui M., Yukawa H. Anaerobic growth of Corynebacterium glutamicum using nitrate as a terminal electron acceptor. Appl. Microbiol. Biotechnol. 2007. V. 75. P. 889-897.

20. Barruiso-Iglesias M., Barreiro C., Flechoso F., Martin J.F. Transcriptional analysis of the $\mathrm{F}_{0} \mathrm{~F}_{1}$ ATPase operon of Corynebacterium glutamicum ATCC 13032 reveals strong induction by alkaline pH. Microbiology. 2006. V. 152. P. 11-21. 
21. Nentwich S.S., Brinkrolf K., Gaigalat L., Huser A.T., Rey D.A., Mohrbach T., Marin K., Puhler A., Tauch A., Kalinowski J. Characterization of the LacI-type transcriptional repressor RbsR controlling ribose transport in Corynebacterium glutamicum ATCC 13032. Microbiology. 2009. V. 155. P. 150-164.

22. Brune I., Jochmann N., Brinkrolf K., Huser A.T., Gerstmeir R., Eikmanns B.J., Kalinowski J., Puhler A., Tauch A. The IclR-type transcriptional repressor LtbR regulates the expression of leucine and tryptophan biosynthesis genes in the amino acid producer Corynebacterium glutamicum. J. Bacteriol. 2007. V. 189. P. 2720-2733.

23. Engels V., Wendisch V.F. The DeoR-type regulator SugR represses expression of ptsG in Corynebacterium glutamicum. J. Bacteriol. 2007. V. 189. P. 2955-2966.

24. Tanaka Y., Okai N., Teramoto H., Inui M., Yukawa H. Regulation of expression of phosphoenolpyruvate:carbohydrate phosphotransferase system (PTS) genes in Corynebacterium glutamicum R. Microbiology. 2008. V. 154. P. 264-274.

25. Brinkrolf K., Ploger S., Solle S., Brune I., Nentwich S.S., Huser A.T., Kalinowski J., Puhler A., Tauch A. The LacI/GalR family transcriptional regulator UriR negatively controls uridine utilization of Corynebacterium glutamicum by binding to cataboliteresponsive element (cre)-like sequences. Microbiology. 2008. V. 154. P. 1068-1081.

26. Krug A., Wendisch V.F., Bott M. Identification of AcnR, a TetR-type repressor of the aconitase gene acn in Corynebacterium glutamicum. J. Biol. Chem. 2005. V. 280. P. 585-595.

27. Nakunst D., Larisch C., Huser A.T., Tauch A., Puhler A., Kalinowski J. The extracytoplasmic function-type sigma factor SigM of Corynebacterium glutamicum ATCC 13032 is involved in transcription of disulfide stress-related genes. J. Bacteriol. 2007. V. 189. P. 4696-4707.

28. Zemanova M., Kaderabkova P., Patek M., Knoppova M., Silar R., Nesvera J. Chromosomally encoded small antisense RNA in Corynebacterium glutamicum. FEMS Microbiol. Lett. 2008. V. 279. P. 195-201.

29. Jochmann N., Kurze A.-K., Czaja L.F., Brinkrolf K., Brune I., Huser A.T., Hansmeier N., Puhler A., Borovok I., Tauch A. Genetic makeup of the Corynebacterium glutamicum LexA regulon deduced from comparative transcriptomics and in vitro DNA band shift assays. Microbiology. 2009. V. 155. P. 1459-1477.

30. Dietrich C., Nato A., Bost B., Le Marechal P., Guyonvarch A. Regulation of ldh expression during biotin-limited growth of Corynebacterium glutamicum. Microbiology. 2009. V. 155. P. 1360-1375.

31. Gao Y.-G., Suzuki H., Itou H., Zhou Y., Tanaka Y., Wachi M., Watanabe N., Tanaka I., Yao M. Structural and functional characterization of the LldR from Corynebacterium glutamicum: a transcriptional repressor involved in L-lactate and sugar utilization. $\mathrm{Nucl}$. Acids Res. 2008. V. 36. P. 7110-7123.

32. Engels S., Schweitzer J.-E., Ludwig C., Bott M., Schaffe S. $c l p C$ and $\operatorname{clpP1P2}$ gene expression in Corynebacterium glutamicum is controlled by a regulatory network involving the transcriptional regulators $\mathrm{ClgR}$ and $\mathrm{HspR}$ as well as the ECF sigma factor $\sigma^{\mathrm{H}}$. Mol. Microbiol. 2004. V. 52. P. 285-302.

33. Letek M., Ordonez E., Fiuza M., Honrubia-Marcos P., Vaquera J., Gil J.A., Mateos L.M. Characterization of the promoter region of $f t s Z$ from Corynebacterium glutamicum and controlled overexpression of FtsZ. Int. Microbiol. 2007. V. 10. P. 271-282.

34. Schreiner M.E., Fiur D., Holatko J., Patek M., Eikmanns B.J. E1 enzyme of the pyruvate dehydrogenase complex in Corynebacterium glutamicum: molecular analysis of the gene and phylogenetic aspects. J. Bacteriol. 2005. V. 187. P. 6005-6018.

35. Inui M., Suda M., Okino S., Nonaka H., Puskas L.G., Vertes A.A., Yukawa H. Transcriptional profiling of Corynebacterium glutamicum metabolism during organic 
acid production under oxygen deprivation conditions. Microbiology. 2007. V. 153. P. 2491-2504.

36. Zhao K.X., Huang Y., Chen X., Wang N.X., Liu S.J. PcaO positively regulates pcaHG of the beta-ketoadipate pathway in Corynebacterium glutamicum. J. Bacteriol. 2010. V. 192. P. $1565-1572$.

37. Okibe N., Suzuki N., Inui M., Yukawa H. Isolation, evaluation and use of two strong, carbon source-inducible promoters from Corynebacterium glutamicum. Lett. Appl. Microbiol. 2010. V. 50. P. 173-178.

38. Frunzke J., Engels V., Hasenbein S., Gatgens C., Bott M. Co-ordinated regulation of gluconate catabolism and glucose uptake in Corynebacterium glutamicum by two functionally equivalent transcriptional regulators, GntR1 and GntR2. Mol. Microbiol. 2008. V. 67. P. 305-322.

39. Letek M., Valbuena N., Ramos A., Ordonez E., Gil J.A., Mateos L.M. Characterization and use of catabolite-repressed promoters from gluconate genes in Corynebacterium glutamicum. J. Bacteriol. 2006. V. 188. P. 409-423.

40. Ruckert C., Milse J., Albersmeier A., Koch D.J., Puhler A., Kalinowski J. The dual transcriptional regulator CysR in Corynebacterium glutamicum ATCC 13032 controls a subset of genes of the McbR regulon in response to the availability of sulphide acceptor molecules. BMC Genomics. 2008. V. 9. Article No. 483.

41. Cramer A., Eikmanns B.J. RamA, the transcriptional regulator of acetate metabolism in Corynebacterium glutamicum, is subject to negative autoregulation. J. Mol. Microbiol. Biotechnol. 2007. V. 12. P. 51-59.

42. Youn J.-W., Jolkver E., Kramer R., Marin K., Wendisch V.F. Characterization of the dicarboxylate transporter DctA in Corynebacterium glutamicum. J. Bacteriol. 2009. V. 191. P. 5480-5488.

43. Schreiner M.E., Riedel C., Holatko J., Patek M., Eikmanns B.J. Pyruvate:quinone oxidoreductase in Corynebacterium glutamicum: molecular analysis of the pqo gene, significance of the enzyme, and phylogenetic aspects. J. Bacteriol. 2006. V. 188. P. 1341-1350.

44. Itou H., Okada U., Suzuki H., Yao M., Wachi M., Watanabe N., Tanaka I. The CGL2612 protein from Corynebacterium glutamicum is a drug resistance-related transcriptional repressor: structural and functional analysis of a newly identified transcription factor from genomic DNA analysis. J. Biol. Chem. 2005. V. 280. P. 38711-38719.

45. Barth E., Barcelo M.A, Klackta C., Benz R. Reconstitution experiments and gene deletions reveal the existence of two-component major cell wall channels in the genus Corynebacterium. J. Bacteriol. 2010. V. 192. P. 786-800.

46. Gerstmeir R., Wendisch V.F., Schnicke S., Ruan H., Farwick M., Reinscheid D., Eikmanns B.J. Acetate metabolism and its regulation in Corynebacterium glutamicum. J. Biotechnol. 2003. V. 104. P. 99-122.

47. Auchter M., Arndt A., Eikmanns B.J. Dual transcriptional control of the acetaldehyde dehydrogenase gene ald of Corynebacterium glutamicum by RamA and RamB. $J$. Biotechnol. 2009. V. 140. P. 84-91.

48. Arndt A., Eikmanns B.J. The alcohol dehydrogenase gene adhA in Corynebacterium glutamicum is subject to carbon catabolite repression. J. Bacteriol. 2007. V. 189. P. 7408-7416.

49. Ruckert C., Koch D.J., Rey D.A., Albersmeier A., Mormann S., Puhler A., Kalinowski J. Functional genomics and expression analysis of the Corynebacterium glutamicum fpr2cysIXHDNYZ gene cluster involved in assimilatory sulphate reduction. BMC Genomics. 2005. V. 6. Article No. 121. 
50. Georgi T., Engels V., Wendisch V.F. Regulation of L-lactate utilization by the FadRtype regulator LldR of Corynebacterium glutamicum. J. Bacteriol. 2008. V. 190. P. 963-971.

51. Hertz G.Z., Stormo G.D. Escherichia coli promoter sequences: analysis and prediction. Methods in Enzymology. 1996. V. 273. P. 30-42.

52. Brok-Volchanski A.S., Masulis I.S., Shavkunov K.S., Lukyanov V.I., Purtov Yu.A., Kostyanicina E.G., Deev A.A., Ozoline O.N. Predicting sRNA genes in the genome of E.coli by the promoter-search algorithm PlatProm. In: Bioinformatics of Genome Regulation and Structure II. Eds. Kolchanov N., Hofestaedt R., Milanesi L. New York: Springer, 2006. P. 11-20.

53. Ozoline O.N., Deev A.A., Arkhipova M.V., Chasov V.V., Travers A. Proximal transcribed regions of bacterial promoters have non-random distribution of A/T-tracts. Nucl. Acids Res. 1999. V. 27. P. 4768-4774.

54. Ozoline O.N., Deev A.A., Trifonov E.N. DNA bendability - a novel feature in E.coli promoter recognition. J. Biomol. Struct. Dynam. 1999. V. 16. P. 825-831.

55. Chasov V.V., Deev A.A., Masulis I.S., Ozoline O.N. Distribution and functional significance of A/T-tracts in promoter sequences of Escherichia coli. Molecular biology. 2002. V. 36. P. 537-542.

56. Ozoline O.N., Deev A.A., Arkhipova M.V. Noncanonical sequence elements in the promoter structure. Cluster analysis of promoters recognized by Escherichia coli RNA polymerase. Nucleic Acids Res. 1997. V. 25. P. 4703-4709.

57. Schneider T.D., Stormo G.D., Gold L., Ehrenfeucht A. Information content of binding sites on nucleotide sequences. J. Mol. Biol. 1986. V. 188. P. 415-431.

58. Huerta A.M., Collado-Vides J. Sigma70 promoters in Escherichia coli: specific transcription in dense regions of overlapping promoter-like signals. J. Mol. Biol. 2003. V. 333. P. 261-278.

59. Huerta A., Francino M.P., Morett E., Collado-Vides J. Selection for unequal densities of s70 promoter-like signals in different regions of large bacterial genomes. PLoS Genetics. 2006. V. 2. Article No. e185.

Received January 21, 2011.

Published February 03, 2011. 